\title{
MAINTENANCE ELECTROCONVULSIVE THERAPY IN SCHIZOPHRENIA
}

\author{
Josef Krepela $^{1}$, Ladislav Hosak ${ }^{2}$, Barbora Pachlova ${ }^{1}$ \& Michal Hrdlicka ${ }^{3}$ \\ ${ }^{I}$ Psychiatric Hospital, Havlickuv Brod, Czech Republic \\ ${ }^{2}$ Department of Psychiatry, Charles University, School of Medicine in Hradec Kralove, \\ University Hospital Hradec Kralove, Czech Republic \\ ${ }^{3}$ Department of Child Psychiatry, Charles University, $2^{\text {nd }}$ Faculty of Medicine, \\ Motol University Hospital, Prague, Czech Republic
}

received: 4.5.2018;

revised: 24.9.2018;

accepted: 22.10 .2018

\section{SUMMARY}

Background: The aim of our retrospective naturalistic observational study was to describe the use of maintenance electroconvulsive therapy (M-ECT) in chronic pharmacoresistant schizophrenia.

Subjects and methods: We delineated 19 cases of chronic pharmacoresistant schizophrenia (females N=12) recently treated with maintenance electroconvulsive therapy at the Havlickuv Brod Psychiatric Hospital in the Czech Republic. Demographic, clinical and treatment variables were recorded.

Results: M-ECT, when applied weekly to monthly mostly over a period of several years, was of no benefit in the treatment of chronic hallucinations and/or delusions. However, it did prove beneficial $(p<0.001)$ in removing chronic serious symptoms like suicidal or violent behavior, automutilation, refusal of food or liquids, stupor or catatonia. Even though almost all of our patients remained hospitalized, we were nonetheless able to transfer them to an unlocked psychiatric ward and let them out for walks or occupational therapy with almost no need for using restraint. No serious adverse side effects of M-ECT were found.

Conclusions: Our study is limited by using only one simple standardized measurement (Clinical Global Impression - Severity) that was retrospective. Another limitation of our retrospective study was that the subjects had not been regularly tested for their cognitive functions. According to our results, M-ECT mitigates the impact of the disease and improves social functioning of the patients. M-ECT does not treat chronic schizophrenia but does make the lives of patients more tolerable. We suggest further research into M-ECT and its clinical application in chronic pharmacoresistant schizophrenia.

Key words: chronic pharmacoresistant schizophrenia - maintenance electroconvulsive therapy - suicidal behavior - violence catatonia

\section{INTRODUCTION}

Shortly after the introduction of electroconvulsive therapy (ECT), the first reports emerged on its use as maintenance treatment for major psychoses, including schizophrenia (Kalinowsky 1943, Moore 1943). With the launch of psychotropic drugs in the 1950s, the use of maintenance ECT (M-ECT) dropped substantially (Grunhaus et al. 1990). Recognition of limitations in the efficacy of antipsychotic drugs and adverse effects of their prolonged use returned interest in ECT as a therapy for treatment-refractory schizophrenia in the 1970s (Fink \& Sackeim 1996).

The American Psychiatric Association (2001) described continuation ECT (C-ECT) as a viable option for long-term management of patients with major depression, bipolar disorder, and schizophrenia. Patients referred for C-ECT should meet the following criteria: 1) a history of illness that is responsive to ECT;

2) either a patient preference for continuation ECT or resistance or intolerance to pharmacotherapy alone; and 3 ) the ability and willingness of the patient (or surrogate consentor) to receive continuation ECT, provide informed consent, and comply with the overall treatment plan, including any necessary behavioral restrictions. The specific timing of C-ECT treatments had been the subject of considerable discussion but evidence supporting any set regimen was lacking (American Psychiatric Association 2001). In many cases, treatments are started on a weekly basis, with the interval between treatments gradually extended to a month, depending on the clinical response.

Concerning the terminology, ECT treatment is considered a continuation one until 6 months after the current episode of mental disorder has remitted. Afterwards, ECT is labeled as a maintenance treatment method (Fink et al. 1996, Prudic 2009). However, many authors do not distinguish between C-ECT and M-ECT, and both terms are used rather synonymously.

The American Psychiatric Association Recommendations (2001) is one of the two official guidelines that exist for maintenance electroconvulsive treatment. The other one is The ECT Handbook by Waite \& Easton (2013). The authors are not aware of any such guidelines having been presented by the World Psychiatric Association (WPA), World Federation of Societies of Biological Psychiatry (WFSBP), European Psychiatric Association (EPA) or European College of Neuro- 
psychopharmacology (ECNP). In the Czech guidelines for the treatment of mental disorders, M-ECT of schizophrenia has not been mentioned (Raboch et al. 2014).

Data on the efficacy of ECT, C-ECT and M-ECT in schizophrenia is limited. In a Cochrane review comparing the efficacy of ECT with antipsychotic drug treatment, 10 short-term studies $(\mathrm{N}=443)$ were identified, with ECT being found less efficacious than antipsychotic drugs (Tharyan \& Adams 2005). One small study $(\mathrm{N}=40)$ showed a more pronounced symptom reduction when ECT was combined with chlorpromazine than with chlorpromazine alone (Wu et al. 1989). A recent 8week, randomized, single-blind study $(\mathrm{N}=39)$ examined the use of ECT as an augmentation to clozapine for treatment-refractory schizophrenia. Fifty percent of the combined ECT plus clozapine group met the response criterion, whereas none of the patients in the clozapine alone group did (Petrides et al. 2015). A randomized, controlled, single-blind trial of C-ECT enrolled 51 patients with treatment-resistant schizophrenia who were followed for 6 months (Chanpattana et al. 1999). Among completers, $40 \%$ of patients relapsed in the combined C-ECT and flupenthixol group, whereas $93 \%$ of patients relapsed in both the group treated with $\mathrm{C}$ ECT alone and that with flupenthixol alone; a highly significant difference.

The aim of our retrospective study was to enrich the scant information on the efficacy and safety of M-ECT as well as to suggest criteria for choosing ECT as a maintenance treatment of schizophrenia.

\section{SUBJECTS AND METHODS}

\section{Subjects}

All patients with schizophrenia, who received maintenance ECT in the Havlickuv Brod Psychiatric Hospital, Czech Republic in November 2017, were involved in our retrospective study. Dr. Josef Krepela, one of the authors of this study, carried out the M-ECT and provided all the relevant information concerning the cases we report here. Because the study is a retrospective chart review, and the patients' data are presented anonymously, no approval of the local Ethics Committee was required. All our patients voluntarily agreed with the hospitalization and M-ECT treatment.

There are a total of 710 beds in the Havlickuv Brod Psychiatric Hospital. The catchment area of the hospital covers 1.1 million inhabitants. In 2015, 453 patients diagnosed with schizophrenia or schizoaffective disorder were hospitalized here.

\section{Methods}

We performed a systematic chart review of the study subjects. A Spectrum 5000Q (Mecta Corporation) with brief-pulse stimulation with the electrodes placed bilaterally was used for the ECT. The described ECT procedures followed the Danish recommended practice (Andersson \& Bolwig 2002). Each patient was treated with bilateral electrode placement following the administration of an anaesthetic and muscle relaxant (Bauer et al. 2009). The frequency of M-ECT was flexible, according to the patient clinical state. The patients were also taking psychotropic medication.

Records of the patients were examined to ascertain demographic, clinical and treatment data as shown in the Results section. The patients were evaluated (Clinical Global Impression; CGI) (Guy 1976) as for overall severity of schizophrenia symptoms based on their medical records both before maintenance ECT had been started and more recently. The study used the first item on the scale (CGI - Severity; CGI-S), with a range from 1 (not ill) to 7 (extremely ill).

\section{Statistical analysis}

Statistical analysis was performed using the Statistical Package for the Social Sciences (IBM SPSS, version 22.0). Descriptive statistics for the sample were used. Following treatment, the related-samples Wilcoxon signed rank test was used for the comparison of baseline CGI-S vs. recent CGI-S.

\section{RESULTS}

\section{Description of the study sample}

The study sample, consisting of 19 patients with schizophrenia (17 undergoing hospitalization, two as outpatients), is described in Table 1. According to our results, the group of schizophrenic patients in whom maintenance ECT was indicated was narrow and highly specific: chronic schizophrenia with a poor prognosis, distinctively pharmacoresistant, frequently even to clozapine. Our patients had been repeatedly hospitalized in the past, and most had undergone permanent hospitalization by the time of our study. They suffered from long-term typical psychotic symptoms like hallucinations and delusions. Apart from this, other important clinical symptoms were present, for example repeated serious suicidal attempts, grave automutilations like the removal of one's own eyeball, refusal of food, liquids and/or medicaments due to psychotic symptoms, agitation, serious violence towards other subjects, stupor or catatonia. Both genders were included in our study, independent of age. We consider the ratio of males to females 7:12 in our study sample as accidental, not reflecting the general schizophrenia sex ratio $1: 1$ in our country. Suitable candidates for M-ECT were identified by the fact that their symptoms improved after an acute ECT but got worse again if ECT was terminated. Our patients continuously used antipsychotic medication when having M-ECT. Recent psychopharmacotherapy consisted of first generation antipsychotics $(\mathrm{N}=18)$, second generation antipsychotics $(\mathrm{N}=17)$, depot first generation antipsychotics $(\mathrm{N}=7)$, anticonvulsants $(\mathrm{N}=3)$ and benzodiazepines $(\mathrm{N}=2)$. The subject's somatic capability to sustain maintenance ECT had to be confirmed by a general practitioner every half year. 
Table 1. Descriptive characteristics of the patients with chronic schizophrenia $(\mathrm{N}=19)$ treated by maintenance electroconvulsive therapy

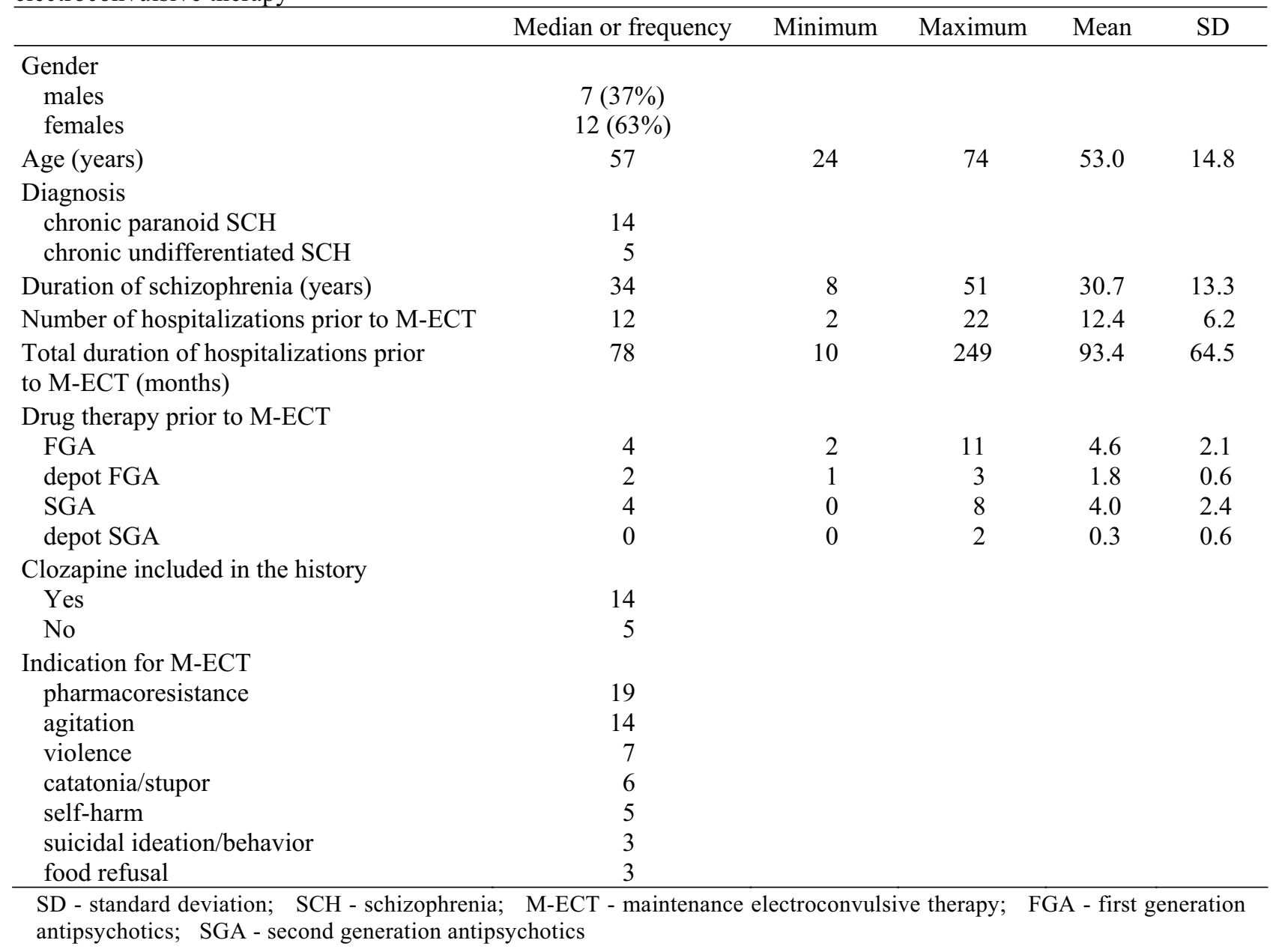

\section{Treatment characteristics of the study sample}

The treatment data is included in Table 2. The typical frequency of M-ECT was 1x/1-4 weeks for several dozen months. The median number of sessions was more than one hundred. Subjects had been hospitalized for several years and had a median CGI - Severity score of 7 prior to the M-ECT and a median recent score of 6 (CGI change: $\mathrm{p}<0.001$ ).

For the most part, maintenance ECT was not effective in treating chronic hallucinations and/or delusions but was able to remove other chronic serious symptoms like agitation, suicidal or violent behavior, automutilation, refusal of food or liquids, stupor or catatonia. In addition, the emotional charge of hallucinations and delusions declined and the patients became self-composed. Individuals receiving M-ECT were able to be transferred to an unlocked psychiatric ward $(\mathrm{N}=17)$ and go out for walks without the need for chemical or other restraint methods. Their sociability was also improved - our patients were able to communicate with the staff better, attend occupational therapy within the mental hospital, participate at social activities organized by the hospital (e.g. trips outside the hospital) and the number of social conflicts with other patients or the staff they were involved in at the ward decreased. Generally, it was possible to reduce the dosage of antipsychotic medication ( $\mathrm{N}=11$ patients) when such a step cut down the probability of extrapyramidal adverse side effects. The amount of prescribed benzodiazepines also diminished significantly ( $\mathrm{N}=12$ patients), with most patients not given this type of psychotropics when such a step prevented, for example, cognitive deficit in geriatric subjects, falls or aspiration of food. The CGI-S score remained high, but the patients' clinical state got better $(\mathrm{p}<0.001)$. The improvement was usually detected within the first weeks of M-ECT and persisted even for many years if treatment was continued. Adverse side effects of MECT were minimal and checked during regular ward rounds. Any memory impairment detected in our subjects $(\mathrm{N}=3)$ was mild. In all our patients, M-ECT was stopped sometime in the past in order to test whether the subject could be maintained without M-ECT, but this therapy was introduced again after the clinical state had substantially deteriorated.

Two patients who were able to be discharged from the hospital after a successful M-ECT treatment differed from the rest of our study sample - they had an excellent social background and their families collaborated with the staff very well. 
Table 2. Treatment characteristics of the patients with chronic schizophrenia $(\mathrm{N}=19)$ treated by maintenance electroconvulsive therapy

\begin{tabular}{|c|c|c|c|c|c|}
\hline & Median or frequency & Minimum & Maximum & Mean & $\mathrm{SD}$ \\
\hline \multicolumn{6}{|l|}{ Frequency of M-ECT } \\
\hline $1 \mathrm{x} /$ week & 5 & & & & \\
\hline $1 \mathrm{x} / 1-2$ weeks & 2 & & & & \\
\hline $1 \mathrm{x} / 1-3$ weeks & 2 & & & & \\
\hline $1 \mathrm{x} / 1-4$ weeks & 3 & & & & \\
\hline $1 \mathrm{x} / 1-8$ weeks & 1 & & & & \\
\hline $1 \times 2-4$ weeks & 4 & & & & \\
\hline $1 \times 4$ weeks & 2 & & & & \\
\hline Total duration of M-ECT (months) & 70 & 13 & 246 & 94.4 & 72.4 \\
\hline Total number of M-ECT sessions & 142 & 50 & 755 & 226.2 & 197.2 \\
\hline CGI-S score prior to M-ECT & 7 & 7 & 7 & 7 & 0 \\
\hline Recent CGI-S score & 6 & 2 & 7 & 5.6 & 1.4 \\
\hline Duration of recent clinical improvement (months) & 69 & 11 & 244 & 93.0 & 72.2 \\
\hline Number of hospitalizations during M-ECT & 1 & 1 & 5 & 1.5 & 1.2 \\
\hline $\begin{array}{l}\text { Total duration of hospitalizations } \\
\text { during M-ECT (months) }\end{array}$ & 62 & 3 & 225 & 79.7 & 66.4 \\
\hline \multicolumn{6}{|l|}{ Adverse side effects of M-ECT } \\
\hline none & 16 & & & & \\
\hline mild memory impairment & 3 & & & & \\
\hline \multicolumn{6}{|l|}{ Clinical effects of M-ECT } \\
\hline none or reduced agitation & 14 & & & & \\
\hline none or reduced violence & 9 & & & & \\
\hline none or reduced catatonia/stupor & 6 & & & & \\
\hline none or reduced self-harm & 5 & & & & \\
\hline reduced psychotic symptoms & 3 & & & & \\
\hline no suicidal ideation/behavior & 3 & & & & \\
\hline no food refusal & 3 & & & & \\
\hline ability to live with family & 2 & & & & \\
\hline
\end{tabular}

\section{DISCUSSION}

A total of 19 subjects (inpatients $\mathrm{N}=17$ ) suffering from chronic schizophrenia underwent M-ECT treatment. These patients already had a history of frequent hospitalization and seemed to be pharmacoresistant, frequently even to clozapine. Five of our patients were never on clozapine because of the possible risk of agranulocytosis, owing to a low blood level of granulocytes. Chronic schizophrenia was defined as one lasting for many years without remission and recently requiring a long-term hospitalization even if many antipsychotics in high doses for a sufficient time had been consecutively applied. Pharmacoresistance was defined as at least two unsuccessful treatments with an antipsychotic from different pharmacological groups in a sufficient dose for a sufficient time (four weeks at least). The typical indications for M-ECT, in addition to this pharmacoresistance, were agitation, violence, catatonia or selfharm. The typical frequency of M-ECT was $1 \mathrm{x} / 1-4$ weeks for several dozen months, totaling more than one hundred sessions. The patients had an original CGI Severity score of 7 , with the most recent score at the time of our study being 6 (median value). The treatment effect of M-ECT on agitation, violence, catatonia, psychotic symptoms and self-harm was remarkable even if other symptoms remained unchanged. The recent clinical state did not permit the patient to be discharged from the hospital, but nonetheless did allow them to be transferred to an unlocked psychiatric ward. We observed almost no adverse side effects of M-ECT, only three subjects developed mild memory impairment.

There are few available studies on the topic of MECT that we can use to compare with our results. Maintenance electroconvulsive therapy as an alternative treatment for refractory schizophrenia and schizoaffective disorders was suggested by Levy-Rueff et al. (2010). They described a clinical cohort of 19 refractory schizophrenic or schizoaffective patients. M-ECT was indicated when a total or a partial failure of neuroleptic treatment had led to an increased frequency of acute episodes or to an increase of symptom intensity, such as suicidal ideas, delusions, and anxiety. There was at least one history of a positive response to treatment with ECT in an acute phase of the disease. The patients were simultaneously treated with antipsychotics. M-ECT appeared efficient on mood symptoms, delusions, anorexia, suicidal behavior, and anxiety symptoms. It 
also improved cooperation and treatment compliance. Under M-ECT, the mean duration of yearly hospitalizations decreased by $80 \%$. The authors also observed an improvement in the daily functioning for most of the patients.

Kristensen et al. (2011) examined charts from 79 patients diagnosed with schizophrenia $(\mathrm{N}=55)$, persistent delusional disorders $(\mathrm{N}=7)$, and schizoaffective disorders $(\mathrm{N}=17)$ and who were treated with ECT between 2003 and 2008 in the greater Copenhagen area. Maintenance ECT was given to 18 patients ( 6 men and 12 women; mean age 45 years; mean disease duration 21 years). Hospitalization and increased pharmacological treatment were insufficient for treating the exacerbation. The initial indications for M-ECT were psychosis, affective symptoms, delirious state, and assaultive behavior. The duration of M-ECT treatment varied between 3 months and 12 years. Most treatment intervals were 2 or 3 weeks. A minority of the subjects received more than 80 ECT sessions, with the maximum being over 125 . Pronounced side effects, such as severe memory loss, were not observed in any patients. All patients treated with M-ECT also received up to five types of antipsychotics. Sixteen patients showed an excellent or good response and two patients showed a moderate response. All 18 patients now live outside the hospital, most in specialised nursing homes, and some are employed as well.

Kristensen et al. (2012) also described a cohort of forensic psychiatric patients with schizophrenia treated with electroconvulsive therapy in Denmark. Four of them were on maintenance ECT therapy with $50-115$ applications. No adverse effects were documented. According to the authors, ECT should not be forgotten as an adjunctive treatment to pharmacological treatment in pharmacoresistant, assaultive psychotic patients.

Based on a naturalistic-observational study in 27 patients suffering from schizophrenia, Hustig \& Onilov (2009) found that ECT proved a valuable and safe augmentative procedure when unsatisfactory response to pharmacological interventions had been demonstrated prior to ECT. This effect was evident despite the chronicity of the illness.

In a review of relevant literature, Palinska et al. (2008) concluded that continuation and maintenance electroconvulsive therapy reduces the risk of schizophrenia relapsing and recurring. This type of treatment is relatively neglected in clinical practice. Most of the research consists of small open studies and case reports. According to the authors, maintenance ECT is a safe and effective treatment. It is suitable for patients who have responded to acute ECT.

Zervas et al. (2012) published a review on using ECT in schizophrenia. ECT beyond the acute course refers to treatments applied at intervals of 1 week to 1 month. According to the authors, use of continuation and maintenance ECT treatments in responders appears beneficial.
The results of our study are similar to the international data stated above, with the exception of discharging patients from the hospital, which was not possible in our inpatients. The explanation is that extramural psychiatric care in the Czech Republic is not yet comparable to the care provided in Western Europe, even though our country has recently undertaken a reform of psychiatric services (http://www.ceskapsychiatrie.cz/index.php/reforma). The current status of organization of mental health care in the Czech Republic was well described by Holly (2016). In particular, there is an overall lack of day care centers, crisis centers, sheltered houses and other services of community care in our country.

A general overview of use of electroconvulsive therapy in Central-Eastern European countries was recently given by Gazdag et al. (2017). ECT practice in this region shows a heterogeneous picture as of utilization rate, prevailing indications and technical parameters. In about half of the countries, schizophrenia is the main indication for ECT.

Based on our results, we suggest the following indication criteria for M-ECT in chronic schizophrenia:

- Chronic severe psychotic symptoms (hallucinations, delusions) + other serious symptoms like agitation, violence, self-harm or catatonia/stupor;

- Pharmacoresistance, including to clozapine;

- At least one positive response to ECT treatment in the acute phase of the disease.

Our retrospective observational study has several limitations. All evaluations were performed by routine clinical examinations at a non-academic inpatient facility. We used only one simple standardized measurement (CGI-S) that was retrospective. However, the CGI has reliably been used in retrospective psychopharmacology research (Friedlander et al. 2001, Hrdlicka \& Dudova 2007) as well as in retrospective M-ECT research (Kristensen et al. 2011, Kristensen et al. 2012). The patients were not randomized to M-ECT, and the rater was not blinded. Clozapine had not been tried in all our patients before maintenance ECT was initiated.

Another limitation of our retrospective study was that the subjects had not been regularly tested for their cognitive functions. The cognition of M-ECT patients could not have been assessed in a valid manner because of the subjects' chronic and severe positive psychotic symptoms and their non-compliance at the examination. The age of the patients also negatively influenced their cognition. Thus the possible diagnosis of ,memory impairment" was established by the attending physician solely based on the patient's behavior at ward, whether memory problems were present or not. In this way, adverse side effects of M-ECT may have been underestimated.

The advantage of our study is its naturalistic arrangement, reflecting the real current clinical practice in the Czech Republic with no restrictions as to patient age, history, clinical state or medication. 
There are several ways to organize further research into maintenance ECT in chronic schizophrenia. Simple naturalistic clinical assessments should be supplemented by schizophrenia rating scales, measurements of quality of life, adverse side effects and cost-effectiveness, detailed evaluations of cognitive functions, brain imaging, and genetic/epigenetic testing in controlled randomized trials. Studies are needed to identify schizophrenia patients who may benefit from M-ECT. Standardized criteria for M-ECT programs should be gradually postulated based on the study results. M-ECT should also be considered in younger patients.

\section{CONCLUSIONS}

In many aspects, ECT treatment in psychiatry has not yet been completely replaced by other methods. It is simple, quick, highly efficient, and has few adverse side effects. The effect of ECT may also be seen in chronic pharmacoresistant schizophrenia. Maintenance ECT mitigates the impact of the disease and improves the social functioning of the patients. From a medical point of view, a great benefit of M-ECT is the reduction in serious and dangerous schizophrenia symptoms and the minimizing of the need for patient restraint. Maintenance ECT does not treat chronic core schizophrenia symptoms, e.g. like negative symptoms, but mostly mitigates behavior problems in these patients, which does make their lives more tolerable. M-ECT is still underused in treatment-refractory patients with schizophrenia. If our study increases the interest of physicians and researchers in this kind of treatment, its aim has been fulfilled.

\section{Acknowledgements:}

The study was supported by the Ministry of Health of the Czech Republic, Czech Health Research Council AZV, grant nr. 16-27243A. All rights reserved.

The manuscript was proofread by Matthew Shane Renfro, BA from the Department of Languages,

Charles University Faculty of Medicine in Hradec Kralove.

Conflict of interest: None to declare.

\section{Contribution of individual authors:}

Josef Krepela - performing M-ECT in the patients, data collection, interpretation of data.

Ladislav Hosak - design of the study, literature searches and analyses, first draft, approval of the final version.

Barbora Pachlova - performing M-ECT in the patients, data collection.

Michal Hrdlicka - design of the study, literature search and analyses, statistical analysis, approval of the final version.

\section{References}

1. American Psychiatric Association: The Practice of Electroconvulsive Therapy: Recommendations for Treatment, Training, and Privileging - A Task Force Report. American Psychiatric Press, Washington, DC, 2001

2. Andersson JE \& Bolwig TG: Electroconvulsive therapy in Denmark 1999. A nation-wide questionnaire study. Ugeskr Laeger 2002; 164:3449-52

3. Bauer J, Hageman I, Dam H, Baez A, Bolwig T, Roed J et al.: Comparison of propofol and thiopental as anesthetic agents for electroconvulsive therapy: a randomized, blinded comparison of seizure duration, stimulus charge, clinical effect, and cognitive side effects. J ECT 2009; 25:85-90

4. Chanpattana W, Chakrabhand MLS, Sackeim HA, Kitaroonchai $W$, Kongsakon $R$, Techakasem P et al.: Continuation ECT in treatment-resistant schizophrenia: a controlled study. J ECT 1999; 15:178-92

5. Fink M, Abrams R, Bailine $S$ \& Jaffe R: Ambulatory electroconvulsive therapy: report of a task force of the Association of Convulsive Therapy. Convuls Ther 1996; 12:42-55

6. Fink $M$ \& Sackeim HA: Convulsive therapy in schizophrenia? Schizophr Bull 1996; 22:27-39

7. Friedlander $R$, Lazar $S \&$ Klancnik J: Atypical antipsychotic use in treating adolescents and young adults with developmental disabilities. Can J Psychiatry 2001; 46:741-5

8. Gazdag G, Dragasek J, Takacs R, Lookene M, Sobow T, Olekseev A et al.: Use of electroconvulsive therapy in Central-Eastern European countries: An overview. Psychiat Danubina 2017; 29:136-40

9. Grunhaus L, Pande AC \& Haskett RF: Full and abbreviated courses of maintenance electroconvulsive therapy. Convuls Ther 1990; 6:130-8

10. Guy W: ECDEU Assessment Manual for Psychopharmacology - Revised. National Institute of Mental Health, Rockville, 1976

11. Holly M: Organization of Mental Health Care in the Czech Republic and Forthcoming Reform. In Hosak L \& Hrdlicka M (eds): Psychiatry and Pedopsychiatry, 29-34. Karolinum, 2016

12. Hrdlicka $M$ \& Dudova I: Risperidone in adolescent schizophrenic psychoses: a retrospective study. Int $J$ Psychiatry Clin Pract 2007; 11:273-8

13. http://www.ceskapsychiatrie.cz/index.php/reforma

14. Hustig $H$ \& Onilov $R$ : ECT rekindles pharmacological response in schizophrenia. Eur Psychiatry 2009; 24:521-5

15. Kalinowsky LB: Electric convulsive therapy, with emphasis on importance of adequate treatment. Arch Neurol Psychiatry 1943; 50:652-60

16. Kristensen D, Bauer J, Hageman I \& Balslev Jorgensen M: Electroconvulsive therapy for treating schizophrenia: a chart review of patients from two catchment areas. Eur Arch Psychiatry Clin Neurosci 2011; 261:425-32

17. Kristensen D, Brandt-Christensen M, Ockelmann HH \& Jorgensen MB: The use of electroconvulsive therapy in a cohort of forensic psychiatric patients with schizophrenia. Crimin Behav Ment Health 2012; 22:148-56

18. Levy-Rueff M, Gourevitch R, Loo H, Olie JP \& Amado I: Maintenance electroconvulsive therapy: An alternative 
treatment for refractory schizophrenia and schizoaffective disorders. Psychiat Research 2010; 175:280-3

19. Moore NP: The maintenance treatment of chronic psychoses by electrically induced convulsions. J Ment Sci 1943; 89:257-69

20. Palinska D, Makowska I, Sobow T, Hese RT \& Kloszewska I: Maintenance electroconvulsive therapy $-a$ review of literature. Psychiatr Polska 2008; 42:819-24

21. Petrides G, Malur C, Braga RJ, Bailine SH, Schooler NR, Malhotra AK et al.: Electroconvulsive therapy augmentation in clozapine-resistant schizophrenia: a prospective, randomized study. Am J Psychiatry 2015, 172: $52-8$

22. Prudic J: Electroconvulsive therapy. In Sadock BJ, Sadock $V A$ \& Ruiz P (eds): Kaplan \& Sadock's Comprehensive Textbook of Psychiatry, 3285-301. Lippincott Williams \& Wilkins, 2009

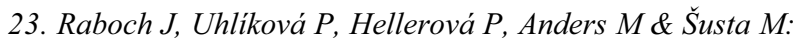
Psychiatrie: Doporučené postupy psychiatrické péče IV. Česká psychiatrická společnost, Prague, 2014

24. Tharyan $P \&$ Adams CE: Electroconvulsive therapy for schizophrenia. Cochrane Database Syst Rev 2005; 2: $C D 000076$

25. Waite $J$ \& Easton A (eds): The ECT Handbook. RCPsych Publications, London, 2013

26. Wu D, She CW, Liu CZ, Cho WL, Quon M, Liu SY et al.: Using BPRS and serial number and picture recall to test the effectiveness of ECT with chlorpromazine versus chlorpromazine alone in the treatment of schizophrenia: 40 cases, single blind observation. Chin J Nerv Ment Disord 1989; 15:26-8

27. Zervas IM, Theleritis $C$ \& Soldatos CR: Using ECT in schizophrenia: A review from a clinical perspective. World J Biol Psychiatry 2012; 13:96-105

\section{Correspondence:}

Prof. Ladislav Hosak, MD, PhD

Department of Psychiatry, University Hospital

Sokolska 581, 50005 Hradec Kralove, Czech Republic

E-mail:hosak@lfhk.cuni.cz 